\title{
O USO DE OBJETOS DE APRENDIZAGEM DE ESTATÍSTICA NA ALFABETIZAÇÃO MATEMÁTICA
}

\author{
Luciane Mulazani dos Santos, Joana Steil Alves e Elisa Henning \\ Universidade do Estado de Santa Catarina, Brasil \\ luciane.mulazani@udesc.br
}

Este trabalho apresenta uma pesquisa realizada no âmbito da Educação Matemática e da Educação Estatística para selecionar e testar objetos de aprendizagem de Estatística que podem ser utilizados como apoio ao processo de Alfabetização Matemática de crianças que cursam o ciclo de alfabetização (primeiro, segundo e terceiro ano do Ensino Fundamental). Foram utilizados repositórios digitais para buscar os objetos de aprendizagem. Os objetos de aprendizagem encontrados foram testados pelos pesquisadores que avaliaram o seu funcionamento, sua aplicabilidade e sua pertinência à proposta de serem recursos de ensino para alfabetização matemática na perspectiva da Educação Estatística. Os resultados da pesquisa foram apresentados na forma de uma análise que mostrou a identificação dos objetos de aprendizagem e seus objetivos, bem como uma avaliação crítica dos testes realizados.

\section{INTRODUÇÃO}

Em nosso país, vivemos um momento de crescente preocupação, inclusive como alvo de políticas públicas educacionais, com a alfabetização matemática das crianças na idade certa para que sejam cumpridas metas de universalização da educação. Vem se tratando, entre outros aspectos, como os professores que ensinam Matemática nos anos iniciais do Ensino Fundamental e também na Educação Infantil devem fazer a organização de seu trabalho pedagógico de modo a considerar as especificidades desta disciplina, o universo da criança e o lúdico como fator essencial que deve estar presente nas práticas docentes. Como parte desse processo de discussão das práticas docentes para o ensino de Matemática nos anos iniciais do Ensino Fundamental, aparecem as questões relacionadas ao ensino de conteúdo de Estatística para as crianças, colocando em debate o tema da alfabetização estatística. Considerando esse cenário e também o fato de que os alunos, hoje, fazem parte de uma geração de nativos digitais, justifica-se a realização de estudos que discutam teorias e práticas que consideram que a tecnologia pode ser usada em processos de alfabetização matemática e estatística de crianças por meio da utilização de objetos de aprendizagem disponíveis com o uso das Tecnologias de Informação e Comunicação (TICs). Nesse contexto, realizamos uma pesquisa como parte de um projeto de conclusão do curso de Licenciatura em Matemática da Universidade do Estado de Santa Catarina que é aqui apresentada na perspectiva da Educação Estatística.

\section{OBJETOS DE APRENDIZAGEM}

Inovações no ensino de Estatística para as crianças podem ser alcançadas com o uso de recursos da Tecnologia de Informação e Comunicação, tais como os objetos de aprendizagem. Por exemplo, jogos digitais, aplicativos, vídeos e áudios são recursos que a criança de hoje - que faz parte da geração de nativos digitais - utiliza para se divertir que podem servir também para tornar a aprendizagem de conteúdos escolares mais significativa. No ensino de Estatística, o uso da tecnologia permite a ampliação das visões críticas a respeito dos fenômenos que estão sendo estudados. Há diferentes definições para objetos de aprendizagem. Neste trabalho, entendemos por objetos de aprendizagem os recursos que podem ser utilizados, com apoio da tecnologia, em diferentes processos de ensino e aprendizagem: segundo Santos (2007), objetos de aprendizagem são recursos digitais reutilizáveis em diferentes situações de ensino e aprendizagem que utilizam o computador em sua mediação e que se apoiam nas Tecnologias de Informação e Comunicação. "Eles contêm as informações para as quais significados são produzidos no processo de construção de conhecimento" (Santos, 2007, p.15) e podem ser utilizados tanto no ensino a distância quanto no ensino presencial ou na mistura de ambos. Objetos de aprendizagem podem formar um conjunto de recursos organizados em um ambiente virtual de aprendizagem ou em repositórios digitais, construídos e acessados via internet, de modo que os alunos possam acessar e discutir informações,

In: M.A. Sorto (Ed.), Advances in statistics education: developments, experiences and assessments. Proceedings of the Satellite conference of the International Association for Statistical Education (IASE), July 2015, Rio de Janeiro, Brazil. 
produzir significados para essas informações e construir conhecimento. Podem ser apresentados na forma de textos, áudios, vídeos, imagens, aplicativos etc..

\title{
EDUCAÇÃO ESTATÍSTICA NA ALFABETIZAÇÃO MATEMÁTICA
}

O Ensino de Estatística na Educação Básica, desde a Educação Infantil, é uma prática orientada, no Brasil, pelos PCNs - Parâmetros Curriculares Nacionais de Matemática (Brasil, 1997) e também pelo RCNEI - Referencial Curricular Nacional para a Educação Infantil (Brasil, 1998). A preocupação com o ensino de conteúdos de estatística para as crianças não é recente. Nos últimos anos, porém, passou-se a discutir com mais ênfase a questão da alfabetização estatística na perspectiva do letramento e da alfabetização matemática, fazendo com que se revissem diversas questões relacionadas ao ensino de Estatística nas escolas, como, por exemplo, a mudança do termo "tratamento da informação", um dos eixos dos PCNs, para "Educação Estatística", entendendo que essa última forma é mais abrangente, englobando o tratamento da informação e também outras fases do ato de pesquisar, ação essencial do trabalho com a alfabetização estatística das crianças.

Guimarães (2014) discute o letramento em estatística no seguinte contexto:

\begin{abstract}
A aprendizagem da Estatística vem sendo proposta desde o Ensino Fundamental como um reflexo das demandas sociais e da complexidade da sociedade que impulsionam o indivíduo na direção de um melhor entendimento de sua realidade. Ser letrado estatisticamente implica saber entender e comunicar dados baseados em informações, sendo capaz de posicionar-se de modo crítico diante delas, a fim de tomar decisões individuais e/ou coletivas. Para o desenvolvimento do pensamento estatístico pelos estudantes, é fundamental proporcionar a vivência de situações nas quais o indivíduo possa pensar um problema, elaborar questões, levantar hipóteses, definir uma amostra, escolher os instrumentos e a forma de coletar os dados, classificar os dados, registrar as informações, interpretá-las e chegar às conclusões possíveis diante do que foi realizado, sempre avaliando cada fase e sua relação com o todo. Enfim, desenvolver o espírito investigativo natural do ser humano. (Guimarães, 2014, p. 4)
\end{abstract}

Esse é o entendimento que demos, em nossa pesquisa, ao conceito de alfabetização matemática no âmbito da Educação Estatística, pressupondo as práticas docentes que levam ao letramento (alfabetização) em Estatística.

\section{A PESQUISA}

A pesquisa que gerou a produção deste trabalho foi realizada ao longo de quatro meses, no segundo semestre de 2014, dentro de um projeto de conclusão de curso de uma aluna da Licenciatura em Matemática da Universidade do Estado de Santa Catarina. A escolha do tema no âmbito da Educação Estatística veio do interesse da aluna - que encerrava o seu período de formação inicial como professora de Matemática - em complementar a sua formação a respeito do ensino de conteúdos de Estatística na Educação Básica. Optou-se por trabalhar com objetos de aprendizagem, recursos da Tecnologia de Informação e Comunicação, para discutir o ensino no ciclo de alfabetização com apoio da tecnologia educacional.

O trabalho se iniciou com estudos teóricos a respeito dos conceitos de Alfabetização Matemática, Educação Estatística, Alfabetização Estatística e Tecnologia Educacional para identificar e sistematizar os critérios de escolha dos objetos de aprendizagem que seriam selecionados e utilizados na pesquisa. Foram selecionados e testados objetos de aprendizagem de Estatística destinados a crianças da faixa etária dos seis aos oito anos, na forma de jogos e aplicativos gratuitos disponíveis na internet. A busca pelos objetos de aprendizagem foi feita em website de pesquisa digitando termos tais como "aplicativos para o ensino de estatística", "jogos de estatística", ou ainda "software para criação de gráficos para o ensino fundamental". Dos resultados encontrados, selecionamos três repositórios - dois em língua portuguesa e um em língua inglesa - que foram importantes por trazerem uma grande quantidade de jogos e aplicativos. São eles: NOAS - Núcleo de computação aplicada para desenvolvimento de objetos de aprendizagem significativa (disponível em http://www.noas.com.br), Escolovar - Qualidade na Educação 
(disponível em http://www.escolovar.org) e Math Playground (disponível em http://www.mathplayground.com ).

Os aplicativos disponíveis para o ensino de Estatística foram acessados e utilizados para verificação se estavam dentro do que era esperado utilizar na pesquisa: para alfabetização estatística de maneira lúdica e investigativa, adequada à faixa etária escolhida. Os objetos de aprendizagem adequados foram testados e analisados para verificação de seu funcionamento, utilização, acessibilidade e adequação à faixa etária. Um deles é apresentado na figura 1.
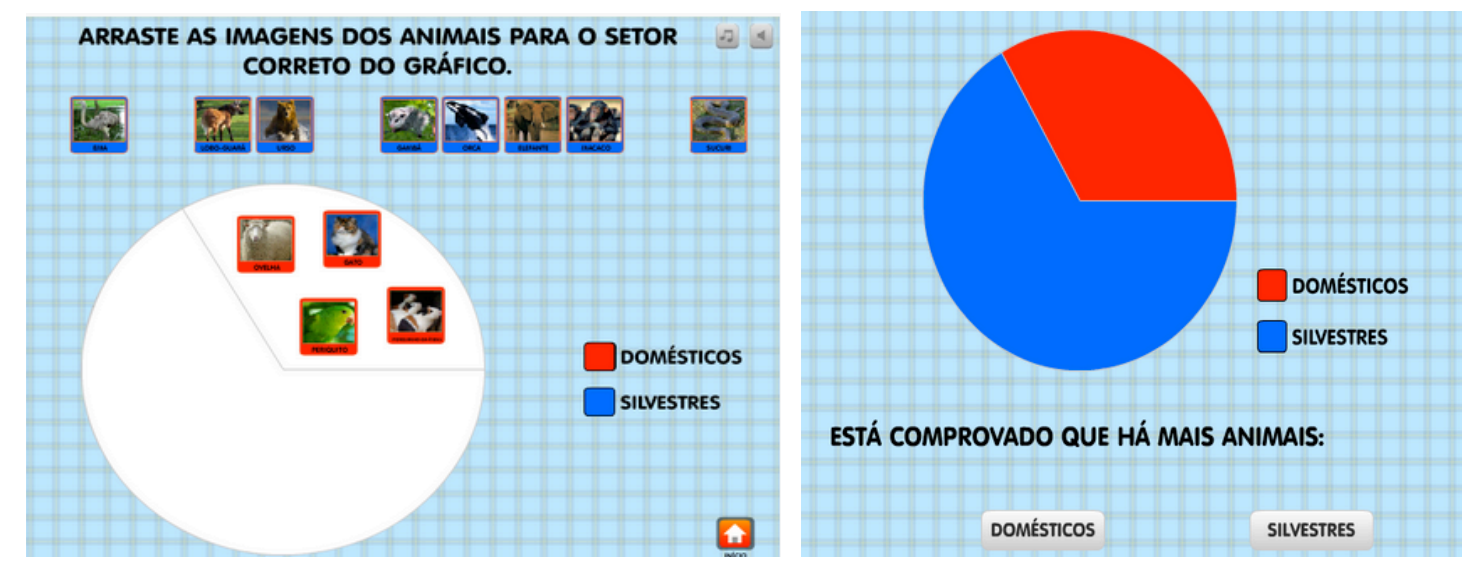

Figura 1. Telas de um dos objetos de aprendizagem estudados na pesquisa.

Disponível em: http://www.noas.com.br/educacao-infantil/ciencias/animais-domesticos-e-silvestres/

Para os testes, foram realizadas atividades e sequências didáticas que buscaram explorar todos os recursos que os objetos de aprendizagem se propunham a oferecer. Alguns dos objetos de aprendizagem testados apresentaram falhas no processo e foram descartados da utilização na etapa seguinte da pesquisa. Por exemplo, em um jogo digital que trabalhava com a contagem de elementos de um conjunto para a construção de gráficos, ainda que o jogador contasse incorretamente a quantidade de elementos, o gráfico era construído, o que induzia o jogador a erros e à compreensão incorreta da análise estatística, comprometendo parte do processo de alfabetização estatística que poderia estar em curso.

$\mathrm{Na}$ sequência da pesquisa, foram realizados testes e análises dos objetos de aprendizagem escolhidos na etapa anterior para elaboração de conclusões a respeito de sua utilização na realização de atividades didáticas de alfabetização estatística. Os objetos de aprendizagem selecionados e a prática discutida fizeram parte de um dos tópicos de um curso de formação de professores, realizado à distância, cujo tema era o uso de tecnologias para alfabetização matemática.

O curso Tecnologias e Alfabetização Matemática foi realizado em parceria com a UDESC como um curso de extensão universitária a distância utilizando a plataforma Moodle e teve a duração de 20 horas no período de 1 a 14 de outubro de 2014. Neste curso, o tópico Educação Estatística foi construído e orientado baseado nos estudos realizados nessa pesquisa. Lá, os trinta e dois professores alfabetizadores matriculados foram convidados a discutirem as alternativas para o uso de objetos de aprendizagem de Estatística no ensino de crianças que participam do ciclo de alfabetização, dados esses que foram levados para a pesquisa. A tela de apresentação do tópico de Educação Estatística é mostrada na figura 2. 
Dia 8 - 10/10/2014- Educação Estatística

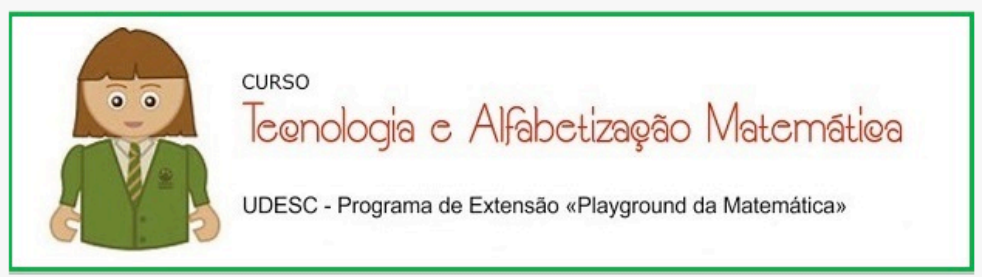

Educação Estatística

Olá Professoras!

Meu nome é Joana, sou acadêmica do curso de Licenciatura em Matemática da UDESC. Eu irei trabalhar com vocês, neste oitavo dia de curso, a Educação Estatística, tema que é parte do meu Trabalho de Conclusão do Curso.

Nosso objetivo é discutir como conteúdos de Estatística podem ser trabalhados nos anos iniciais do Ensino Fundamental, na perspectiva da Alfabetização Matemática, utilizando recursos tecnológicos.

Bom Aprendizado!

Figura 2. Tela de apresentação do curso de Educação Estatística realizado via Moodle.

É importante destacar que foram selecionados e discutidos objetos de aprendizagem que poderiam ser utilizados no ensino de Estatística de modo a permitir ao aluno do ciclo de alfabetização atingir os seguintes objetivos para a alfabetização estatística: ler, interpretar e fazer o uso das informações expressas na forma de ícones, símbolos, signos e códigos em diversas situações e em diferentes configurações (anúncios, gráficos, tabelas, rótulos, propagandas), para a compreensão de fenômenos e práticas sociais; formular questões que gerem pesquisas e observações para coletar dados quantitativos e qualitativos; coletar, organizar e construir representações próprias para a comunicação de dados coletados (com ou sem o uso de materiais manipuláveis ou de desenhos); ler e interpretar listas, tabelas simples, tabelas de dupla entrada, gráficos; elaborar listas, tabelas simples, tabelas de dupla entrada, gráfico de barras e pictóricos para comunicar a informação obtida, identificando diferentes categorias; produzir textos a partir da interpretação de gráficos e tabelas; problematizar e resolver situações a partir das informações contidas em tabelas e gráficos; reconhecer e diferenciar situações determinísticas e probabilísticas; identificar a maior ou menor chance de um evento ocorrer.

As análises feitas sobre os objetos de aprendizagem, bem como os comentários registrados pelos professores que participaram do curso a distância e utilizaram tais objetos de aprendizagem, foram organizados e apresentados no trabalho, que indicaram como principais resultados representativos do universo do grupo de discussão envolvido e, portanto, particulares a ele: a maioria dos objetos de aprendizagem disponíveis na internet são em língua inglesa, o que dificulta a sua utilização por aqueles que não dominam esse idioma; é preciso que os professores testem os objetos de aprendizagem antes de utilizá-los com os alunos, pois eles podem apresentar erros de desenvolvimento que podem prejudicar a aprendizagem dos conteúdos de estatística; a alfabetização estatística das crianças dos anos iniciais do Ensino Fundamental pode ser favorecida com o uso da tecnologia, pois assim os processos de investigação e de resolução de problemas ganham alternativas diferentes do que se for utilizado apenas o ambiente lápis e papel ou quadro e giz.

\section{CONSIDERAÇÕES FINAIS}

A realização desta pesquisa nos permitiu ampliar os conhecimentos acerca do conceito de alfabetização estatística e das práticas que podem ser realizadas, no ciclo de alfabetização, para ensinar conteúdos de estatística utilizando recursos tecnológicos - os objetos de aprendizagem - de forma adequada à faixa etária das crianças de maneira investigativa e lúdica. Além disso, pudemos compartilhar as nossas descobertas com professores alfabetizadores que participaram do curso de formação à distância que foi oferecido como parte do projeto de pesquisa. Foi possível, desta forma, analisar como os recursos da Tecnologia de Informação e Comunicação podem ser utilizados pelo professor da Educação Básica tanto para ensinar os seus alunos quanto para construir novos conhecimentos em cursos que complementam a sua formação. A questão da Alfabetização Matemática na perspectiva da Educação Estatística e da Alfabetização Estatística 
nos mobilizaram a continuar desenvolvendo novas pesquisas sobre práticas e pesquisas que vêm sendo realizada em nosso país no ciclo de alfabetização.

\section{REFERÊNCIAS}

Brasil. (1998). Ministério da Educação e do Desporto. Secretaria de Educação Fundamental.

Referencial curricular nacional para a educação infantil. Brasília: MEC/SEF.

Brasil. (1997). Secretaria de Educação Fundamental. Parâmetros curriculares nacionais. Brasília: $\mathrm{MEC} / \mathrm{SEF}$.

Guimarães, G. (2014) Estatística e combinatória nos anos iniciais de escolarização. Salto para o Futuro: Estatística e combinatória no ciclo de alfabetização, Ano XXIV, Boletim 6, 4-5.

Santos, L. M. (2007) Produção de Significados para Objetos de Aprendizagem: de autores e leitores para a Educação Matemática. Dissertação (Mestrado em Educação). Curitiba: UFPR. 